\title{
¿Qué mueve a las jóvenes a participar? Activismo de género y construcción de identidades en estudiantes de escuelas secundarias de Córdoba, Argentina
}

\author{
What moves young women to participate? \\ Gender activism and identity becoming in \\ student of secondary school from Córdoba, \\ Argentina
}

\section{O que motiva as jovens a participar. Ativismo de gênero e devires identitários em estudantes do ensino médio de Córdoba, Argentina}

\author{
Marina Edith Tomasini \\ ORCID ID: 0000-0003-4357-287X \\ CONICET-Universidad Nacional de Córdoba, Argentina
}

Autor referente: marinatomasini@hotmail.com

Historia editorial

Recibido: $12 / 10 / 2018$

Aceptado: 05/05/2020

\section{RESUMEN}

Este artículo aborda la participación de jóvenes, estudiantes de escuelas secundarias de Córdoba, Argentina, en movilizaciones convocadas por colectivos feministas. Se analizan los motivos que las llevan a concurrir a las marchas, los temas que les preocupan y las demandas que plantean. El interés teórico gira en torno a sus devenires identitarios, a partir de instancias de participación donde luchan por producir transformaciones

en las relaciones sexo-genéricas.La identidad como un devenir implica pensarla como incompleta, en proceso y abierta a la posibilidad de transformación.

Se realizaron 28 entrevistas breves grabadas a jóvenes durante las marchas (años 2017 y 2018) y se hicieron siete entrevistas grupales en profundidad con estudiantes que participaron en las movilizaciones. Algunos ejes de indagación fueron: conocimiento y posicionamiento acerca 
de las consignas propuestas por el colectivo organizador; motivos para ir a la movilización, aspectos organizativos y vivencias afectivas durante la marcha; temas y situaciones vinculadas con género y sexualidad que les preocupan en sus realidades cotidianas.

En el escrito se desarrollan algunos ejes analíticos tales como: (a) los motivos para ir a las marchas; aquí emerge un abanico amplio de situaciones que interpretan como desigualdades, discriminaciones, injusticias y violencias, que advienen al relato entrelazadas con sensaciones de malestar, enojo o dolor, por cuya transformación luchan (b) los marcadores sociales predominantes desde los cuales construyen su identidad en los relatos: género, generación y posicionamiento feminista. Finalmente se discute el devenir identitario desde tres procesos interrelacionados: agencia, intersubjetividad y conciencia.

Palabras clave: Feminismo; activismo juvenil; identidad; narrativa

\section{ABSTRACT}

This paper addresses participation in feminist mobilizations of youngsters that attend secondary education in Córdoba, Argentina. It aims at comprehending their concurrence to public manifestations, issues of concern and demands. The theoretical interest spins around her identity becoming from their participation in actions oriented to the transformation of sex and gender relationships. Considering identity as a matter of becoming implies that it is incomplete, in process and open to transformation.

For this purpose, we carried out twentyeight brief recorded interviews with youngsters during the public manifestations (in 2017 and 2018) and seven group interviews with students who participated in mobilizations. Some inquiry axes were: knowledge and positioning about the slogans proposed by the organizing collective; reasons to mobilize; organization and affective experiences during the manifestation; issues and situations regarding gender and sexuality to which they are concerned in their everyday realities.

Two analytical topics are developed in the paper: (a) reasons for attending manifestations; this implies a variety of situations interpreted as inequalities, discriminations, injustices and violence, that come into to the narrative interlaced with feelings of discomfort, anger and pain they fight to transform. (b) The predominant markers through which they construct their identity throughout the narratives: gender, generation and feminist positioning. Finally, we discuss the identity becoming considering three interrelated processes: agency, intersubjectivity and conscience

Keywords: Feminism; youth activism; identity; narrative

\section{RESUMO}

Este artigo analisa a participação das jovens, estudantes de escolas secundárias (Córdoba, Argentina), em mobilizações convocadas por coletivos feministas. O objetivo é analisar os sentidos que as mobilizam para ir às 
manifestações, as questões que as preocupam e as demandas que se indagam. $O$ interesse teórico gira em torno de seus devires identitários, a partir de instâncias de participação onde lutam para produzir transformações nas relações sexogenéricas. Conceber a identidade como um devir implica em pensá-la como algo incompleto, em processo e aberto à possibilidade de transformação.

Foram realizadas vinte e oito entrevistas curtas gravadas com jovens durante as manifestações $(2017 \mathrm{e}$ 2018) e sete entrevistas mais complexas com grupos de estudantes que participaram das mobilizações. Alguns eixos de investigação foram: conhecimento e posicionamento sobre as diretrizes propostas pelo coletivo organizador; razões para ir à mobilização, aspectos organizacionais e experiências afetivas durante a manifestação; e questões e situações relacionadas a gênero e sexualidade que lhes preocupam em suas realidades cotidianas.

O trabalho escrito se desenvolve em dois eixos analíticos: (a) as razões para ir às manifestações; aqui surge uma ampla gama de situações que são interpretadas como desigualdades, discriminação, injustiça e violência que aparecem nos relatos e que estão entrelaçadas a sentimentos de desconforto, esgotamento, raiva ou dor, por cuja transformações elas lutam. (b) os marcadores sociais predominantes a partir dos quais eles constroem sua identidade nos relatos: gênero, geração e posicionamento feminista. Finalmente, é discutido o deviridentitários a partir de três processos inter-relacionados: agência, intersubjetividade e consciência.

Palavras chave: Feminismo; ativismo juvenil; identidade; narrativa

L as luchas de los feminismos han recorrido, desde el siglo XIX, un dilatado camino en pos de revertir procesos de opresión, exclusión y explotación instaurados en las sociedades. Desde hace varias décadas, en nuestro continente, el movimiento de mujeres viene reclamando por los derechos al denunciar la violencia de género, la doble y triple jornada de trabajo, la falta de políticas de salud reproductiva y la discriminación laboral (Di Marco, 2010).

En el caso de Argentina, los activismos feministas han desarrollado acciones heterogéneas para evidenciar las violencias, discriminaciones y restricciones en el acceso a derechos. Recientemente, en el año 2015, irrumpe en la escena social el Colectivo Ni Una Menos; sus manifestaciones más visibles han sido las marchas masivas convocadas en junio, las del 8M -en ocasión del Paro Internacional de 
Mujeres- y las movilizaciones ocurridas durante el tratamiento de la Ley de Interrupción Voluntaria del Embarazo en el año 2018. En este movimiento conviven, no sin tensiones, sectores partidarios y no partidarios muy distintos y los reclamos son variados: por la violencia, el acoso y los femicidios, por la discriminación laboral y la feminización de la pobreza, por los derechos sexuales y (no) reproductivos, por la autonomía de los cuerpos, entre otros.

En este escenario, distintos sectores de la juventud se politizan a partir del reconocimiento y cuestionamiento de las relaciones de género y sexualidad como una forma de desigualdad, subordinación y poder. Los activismos de género surgidos en la coyuntura que instaló el Ni Una Menos señalan un hito en la historia de la participación de las jóvenes en el proyecto cultural y político del feminismo local, al tiempo que instalan un nuevo escenario de encuentro intergeneracional (Elizalde \& Mateo, 2018). Las chicas, como lo ha analizado Silvia Elizalde (2018a), forman parte de una generación que goza de logros decisivos en materia de género y sexualidad, los que se reflejan en un conjunto significativo de leyes que han sido resultado de luchas feministas por parte de mujeres que las precedieron largamente en la ocupación del espacio público para hacer oír sus demandas. Pero, al mismo tiempo, sus reclamos y peleas adquieren una particular marca generacional (Lares, Nimo, Morales \& Tomasini, 2019), como las que encabezan en relación con los micro machismos, el hostigamiento callejero o el acoso sexual en las redes, en las escuelas y las universidades.

Lo que resulta especialmente significativo es la visibilidad que han adquirido como sujeto político las jóvenes "adolescentes" en un contexto que, por un lado, las idealiza como fuerza del cambio o agentes de resistencia y, por otro lado, las deslegitima con imágenes negativas, que refuerza el lugar de la minoridad que necesita ser tutelada. Los estudios de participación política juvenil en el contexto latinoamericano (Lopes de Oliveira \& Almeida Camilo, 2014; Vázquez, Vommaro, Núñez, \& Blanco, 2017) han 
venido señalando que los temas de género y sexualidad ingresaron en la agenda del activismo juvenil o forman parte de los temas centrales que ocupan a colectivos de jóvenes. La disputa por la transformación de significados, prácticas y estilos de experimentar el cuerpo, la sexualidad y el género resalta como un aspecto clave (Ortiz-Ruiz, 2016).

El activismo es capilar en múltiples ámbitos: en las calles, en las redes, en la escuela, en la familia, en espacios de sociabilidad, diversión y en las salidas nocturnas. En Córdoba, como en otras ciudades del país, muchas escuelas secundarias han sido un lugar para el reclamo y crítica a la discriminación sexo-genérica a través de protestas o demandas para modificar reglamentos de vestimenta o para que se atienda la situación de estudiantes trans en lo relativo al uso de baños; mediante acciones entendidas por sus protagonistas como estrategias militantes para colocar algunos temas de género en la escena escolar (Baez, 2014), la elaboración de proyectos contra la violencia en el noviazgo u organización de charlas sobre aborto por parte de agrupaciones de estudiantes.

Todo ello requiere poner en tensión una caracterización más o menos generalizada que señalaba la indiferencia o el rechazo de las más jóvenes hacia el feminismo. Según esta perspectiva, este movimiento sería percibido como obsoleto en un contexto posfeminista, donde las mujeres habrían alcanzado la igualdad en distintos ámbitos (Ringrose \& Renold, 2016). La despreocupación y el desencanto que las chicas tienen con el feminismo y los motivos para no comprometerse en sus luchas políticas se han asociado con el "velo de igualdad", las presiones mediáticas hacia el individualismo, el estigma de ser feminista -y sus repercusiones en la propia subjetividad- y el escaso impacto del movimiento en las más jóvenes (Gómez Ramírez \& Reyes Cruz, 2008).

El protagonismo de las jóvenes "adolescentes" en los feminismos locales requiere prestar atención a este fenómeno sociocultural para comprender cómo producen sus 
propios significados y crean su identidad como feministas o activistas. Desde los Girlhood Studies -campo que conjugaestudios culturales feministas, de infancia y juventud- se ha subrayado la necesidad de tomar en cuenta la subjetividad política de este sector de la juventud (Renold \& Ringrose, 2008; Ringrose \& Renold, 2016). Estas autoras señalan que, para entender su implicación en el feminismo, se requiere explorar más allá de las expresiones normativas de la participación, tal como es definida por adultos. Al mismo tiempo, parecen limitados los marcos dicotómicos que conciben la adscripción al feminismo o bien el rechazo del mismo, ya que los acercamientos a este movimiento pueden ser heterogéneos, en algunos casos ejercitando la crítica a la feminidad normativa sin asumir una identidad feminista y en otros identificándose solo con algunas demandas y exigencias que interpelan las condiciones de sexualidad y género. Es así que las formas de participación y las acciones son diversas, en coincidencia con lo documentado en distintos estudios de la región sobre participación política juvenil: el uso de lenguajes no convencionales, con utilización de redes sociales, y la co-existencia de formas asociativas tradicionales como la vinculación a partidos políticos o agremiaciones estudiantiles- con la articulación eventual de actores en función de la identificación común con un tema (Alvarado \& Vommaro, 2010; Lopes de Oliveira \& Almeida Camilo, 2014; Ortiz-Ruiz, 2016).

Este artículo centra su interés teórico en los devenires identitarios de un conjunto de jóvenes a través de las acciones de lucha transformar las relaciones sexo-genéricas, en el escenario instalado por el movimiento Ni Una Menos en Córdoba. La identidad como un devenir implica pensarla como incompleta, en proceso y abierta a la posibilidad de transformación: "no 'quiénes somos' o 'de dónde venimos' sino en qué podríamos convertirnos" (Hall, 2003, p. 17-18). Esta perspectiva se interesa por las rupturas y los micro movimientos (Renold \& Ringrose, 2008) en los que se van trasformando los significados de sí, de sus grupos cercanos o de sus colectivos de 
referencia en función de la implicación en determinados espacios, actividades u organizaciones.

Desde la Psicología Cultural, Bruner (2003) propone que creamos y recreamos la identidad mediante la narrativa: "el yo es un producto de nuestros relatos y no una cierta esencia por descubrir cavando en los confines de la subjetividad" (p. 122). La cultura, que ofrece el marco de sentido para estos relatos, contiene narraciones alternativas acerca de qué es el yo o qué podría ser. A su vez, estas ideas son relacionales, dependen de las nociones de quiénes son los otros, a los que podemos considerar parecidos o diferentes (Bruner, 2003). En consonancia con este enfoque se considerarán los micro relatos producidos por estudiantes de escuelas secundarias con el objetivo de analizar la atribución de significados a su participación en las marchas y, de este modo comprender, la construcción de identidades vinculadas con estos contextos de acción.

\section{Metodología y caracterización de los grupos entrevistados}

Se realizaron registros (notas de campo y fotográfico) y entrevistas breves grabadas, con preguntas estandarizadas de respuesta abierta, a jóvenes, que se ubicaban en los alrededores de la bandera de la Federación de Estudiantes Secundarios de Córdoba (FES), durante las marchas Ni Una Menos $(2017,2018)$ y $8 \mathrm{M}$ (2018). Además de relevar la edad y datos de sus escuelas y centros de estudiantes, los ejes de indagación fueron: i. conocimiento y posicionamiento acerca de las consignas y reclamos propuesto por el colectivo organizador en cada movilización; ii. participación de los grupos: motivos para concurrir y vivencias afectivas durante la marcha; iii. temas y situaciones vinculadas con género y sexualidad que les preocupan en las realidades cotidianas de sus escuelas; acciones que se realizan al respecto en la institución educativa. 
Para el relevamiento en las marchas el criterio de muestreo seguido fue por accesibilidad. En este caso, jóvenes que aceptaran responder nuestras preguntas. Se procuró entrevistar a quienes llevaban banderas de sus centros estudiantiles como a quiénes no portaban tales emblemas, a fin de acceder a información sobre distintas conformaciones grupales. La sobre representación de chicas se debe a que su participación fue mayoritaria en las marchas. Se tomaron 28 entrevistas breves.

Tabla 1

Sexo, edad y tipo de escuela de estudiantes entrevistados

\begin{tabular}{ccccccccc}
\hline & & \multicolumn{3}{c}{ Edades } & & \multicolumn{2}{c}{ Tipo de gestión de la escuela } \\
Mujer & Varón & 14 & 15 & 16 & 17 & Público & Privado \\
\hline 27 & 1 & 8 & 5 & 7 & 8 & 12 & 16 \\
\hline
\end{tabular}

De las escuelas públicas, 7 corresponden a colegios preuniversitarios dependientes de la Universidad Nacional de Córdoba, 4 a institutos provinciales de enseñanza media (IPEM) y una a un colegio técnico. Dentro de los colegios privados, 7 son escuelas confesionales (5 católicas y 2 luteranas).

Además del relevamiento realizado en las marchas, se hicieron siete entrevistas grupales en profundidad, alrededor de los ejes ya señalados, con grupos de estudiantes que participaron en las movilizaciones. Para el muestreo se combinó la selección de distintos contextos institucionales y diferentes tipos de agrupamientos estudiantiles, de modo que se entrevistaron estudiantes de escuelas de gestión pública -provinciales y preuniversitarias- y de colegios de gestión privada confesionales y no confesionales-. A su vez, los grupos corresponden a centros de estudiantes, a espacios que se organizan por fuera de tales órganos de representación 
estudiantil (CAJ y Secretaria de diversidad) y a asociaciones espontaneas para ir a las marchas, denominadas como 'autoconvocadas'. Esto permitió conocer a grupos con diferentes trayectorias de participación y con distintas percepciones acerca de sus contextos escolares. Así es como varias chicas y algunos chicos decían participar en diferentes marchas sobre temas sociales y de derechos humanos como parte de las actividades de sus centros. Otras, en cambio, sólo iban a las marchas convocadas por el colectivo Ni Una Menos como ‘autoconvocadas', 'independientes' o 'por su cuenta'. Algunas indicaron que los temas de género no forman parte de las actividades de sus centros de estudiantes y se posicionaron de manera crítica al respecto. En cuanto a sus escuelas, en algunos casos eran consideradas como espacios promotores de debates y participación, hablaban de colegios 'progre' [progresista], 'con conciencia', que 'promueve el debate' y forma para 'pensar críticamente'. En otros casos consideraban que solo un conjunto limitado de docentes hablaba ocasionalmente de temas como violencia de género, diversidad sexual o aborto.

Tabla 2

Marchas relevadas y tipos de agrupaciones estudiantiles

\begin{tabular}{|c|c|c|c|}
\hline Año & Marcha & Entrevistas por Escuelas & Tipo de agrupación \\
\hline 2016 & $\begin{array}{l}\mathrm{Ni} \text { Una } \\
\text { Menos }\end{array}$ & $\begin{array}{l}-2 \text { en una escuela } \\
\text { confesional católica } \\
-1 \text { en IPEM }\end{array}$ & $\begin{array}{l}\text {-Grupo de chicas "autoconvocadas" } \\
\text { ( } 5 \text { chicas en cada entrevista) } \\
\text {-Grupo de estudiantes de un Centro } \\
\text { de Actividad Juvenil, CAJ ( } 4 \text { chicas y } \\
\text { un chico) }\end{array}$ \\
\hline 2017 & $\begin{array}{l}\mathrm{Ni} \text { Una } \\
\text { Menos }\end{array}$ & $\begin{array}{l}-2 \text { en colegios } \\
\text { preuniversitarios (i. y ii.) }\end{array}$ & $\begin{array}{l}\text {-CE (i. } 3 \text { mujeres y } 1 \text { varón; ii. } 2 \\
\text { varones y una mujer) }\end{array}$ \\
\hline & & $\begin{array}{l}-1 \text { en colegio con modalidad } \\
\text { de cooperativa }\end{array}$ & -CE (3 Mujeres y 1 varón) \\
\hline 2018 & $8 M$ & -1 en una IPEM & $\begin{array}{l}\text {-Secretaria de Diversidad ( } 7 \text { chicas y } \\
\text { un chico) }\end{array}$ \\
\hline
\end{tabular}


Se realizó análisis de contenido temático con el fin de identificar aspectos emergentes respecto de los ejes de indagación, lo que permitió construir las líneas analíticas que se presentan en las secciones siguientes.

En la toma de entrevistas participaron dos estudiantes de Psicología que se encontraban realizando su Trabajo Final de grado para obtener la licenciatura. Previo a cada entrevista, breve o en profundidad, se informó a las y los participantes sobre objetivos del proyecto, metodología de investigación y destino de los datos recabados. Se aplicó el asentimiento libre, expreso e informado.

Si bien las denominaciones que aparecen en el texto - chicas y chicos o mujeres y varones- resultan binarias, en las entrevistas preguntamos ¿cuál es tu sexo? con el fin de captar el modo de denominación de las personas entrevistadas. Las respuestas fueron ‘mujer' o 'femenino' y ‘varón' o 'masculino'. En este marco, la mayoría de los análisis se refieren a las chicas, en tanto ellas han sido las protagonistas principales de las movilizaciones analizadas, no obstante lo cual aparecen marcas de género en el uso de los artículos a lo largo del escrito cuando las proposiciones construidas también comprenden a varones. Finalmente, se utiliza comilla simple para señalar palabras o frases textuales producidas en las entrevistas.

Las marchas como espacios para el ejercicio de la crítica social. Los motivos para marchar

En un clima festivo, entre perfomances, cantos, corridas, bengalas y risas encontramos en las marchas a grupos numerosos de jóvenes en los alrededores de la bandera barredora de la Federación de Estudiantes Secundarios de Córdoba. Los rostros y partes del cuerpo pintados, los cabellos con tinturas de colores intensos, los pañuelos verdes en cuellos o torsos forman parte de la escena. En carteles y pancartas se pueden leer frases referidas a la violencia: "Quien ama no mata, no humilla, ni maltrata", "Contra la violencia machista todas las manos son necesarias", 
"Quiero salir sin que mi mamá tenga miedo". Se manifiestan reclamos en torno a la autonomía corporal, tales como: "No es no" o "Yo elijo como me visto" así como a la reivindicación del feminismo como experiencia transformadora también: "El feminismo me cambió la vida, no voy a dejar que tu machismo me la quite". En distintos slogans predomina un lenguaje de lucha que construye una posición de agencia para la transformación social y cultural: "Aquí se respira lucha”, "Mujer bonita es la que lucha”, "Ni callada ni sometida, declarándole la guerra al Estado femicida".

Una de las preguntas que realizamos en todas las marchas fue: ¿Qué te motiva a venir? A partir de esa interrogación surgen micro relatos sobre situaciones que interpretan como desigualdades, discriminaciones, injusticias y violencias entrelazadas con sensaciones de malestar, hartazgo, enojo o dolor- por cuya transformación luchan. Esto ya señala una construcción de sí mismas desde un marco de agencia e intersubjetividad, ligado a la creencia y la confianza que la acción colectiva que protagonizan modifica o contribuye a cambiar la situación que motiva su salida a la calle a reclamar.

Además del foco puesto en la violencia y los femicidios, están allí para reclamar por los derechos sexuales y (no) reproductivos. En este tópico, es notable cómo desde las primeras marchas en 2015 hasta las últimas movilizaciones en 2018 el reclamo por aborto legal, seguro y gratuito empieza a hacerse cada vez más presente y a saturar en las respuestas como un motivo de movilización. En casi todas las respuestas del 8M del último año indagado aparece como motivo central, al compás de los debates mediáticos y de las acciones del movimiento feminista, en especial de la Campaña por el Derecho al Aborto Legal, Seguro y Gratuito.

También marchan y se movilizan porque quieren un cambio cultural, que se refleje en los significados y en las prácticas cotidianas en sus relaciones próximas. Porque les molesta el 'machismo', la desigualdad de expectativas y normativas en un amplio rango de asuntos que incluye la práctica de deportes, la vestimenta o la sexualidad. 
Aquí es donde más se observa la afectación personal. Si bien en temas como la violencia o el acoso muchas se perciben como potenciales "víctimas" por ser mujeres y jóvenes, es en el terreno de las actitudes diarias donde aparece la primera persona, trayendo alguna anécdota breve, recordando comentarios de familiares, docentes, amigos o compañeros por la ropa que usan, porque no se depilan, no se maquillan o no cuidan su arreglo personal. Las primeras participaciones en las marchas parecen tener un efecto desnaturalizador, lo que allí perciben (carteles, perfomances, cantos) les sirve de espejo donde ven reflejadas las restricciones que imponen los estereotipos de género:

-Capaz que ver esta problemática desde otro punto o el hecho de decir "ah estás gorda" "pintate", que son estereotipos que están como muy marcados y decís: "bueno, eso también es violencia de género".

-Obviamente que la violencia y el maltrato físico está mal, pero cuando vos ves los carteles de la gente que dice que los piropos en la calle también son violencia de género y el problema es mucho más grande que lo que las personas a veces ven.

- Las actitudes más cotidianas que dicen: "bueno, arreglate o pintate, vestite linda para salir o tenés que estar prolijita." ¿Y si me gusta estar toda despeinada, digamos? En pijama en la calle (risas) (Tomasini y colaboradoras, entrevista grupal a autoconvocadas, 7 de junio de 2016).

El malestar ante la prescripción de las formas corporales y la presión de los ideales de perfectibilidad física, que ha instaurado la cultura hegemónica de la belleza como cúspide de la feminidad (Tincknell, 2011), puede ser politizado en la medida que es vuelto visible y compartido en la escena pública, a través de un conjunto de acciones significantes ya sean verbalizadas, actuadas o portadas icónicamente.

Finalmente, se suman a la marcha porque reivindican el derecho a la voz y a la participación: 'alzar la voz', 'tener voz', 'hacerse oír', 'quejarse'. De hecho, un lema que 
quedó instalado en las marchas en el año 2018 es: "Ahora que sí nos ven". Las chicas quieren ser escuchadas y reconocidas como sujetos con voz propia y con capacidad de definirse a sí mismas y a sus realidades. Es un cuestionamiento a la visión minorizante y la primacía adulta para circunscribir cuál es su lugar en la sociedad:

Estaría bueno que los jóvenes tengamos más voz, porque somos afectados y afectamos

Es ser parte de la lucha, del movimiento de decir "bueno yo pienso esto, y voy con eso" no quedarte en tu casa diciendo "ay si yo estoy a favor del aborto" ¿y desde tu casa que haces? No, es salir a marchar y luchar por lo que quiero, por lo que quiero en el futuro, por lo que quiero para mí y todos. (Tomasini y colaboradoras, entrevista grupal, centro de estudiante, 14 de junio de 2017).

Esta demanda adquiere una especial carnadura en aquellas jóvenes que vienen de contextos educativos percibidos como restrictivos, especialmente los confesionales, aunque no solamente:

El colegio no te da mucho lugar por ser católico. En mi colegio no veo mucha participación. Te dicen feminazi. No se animan a hablar, no se animan a participar, están negados. (Tomasini y colaboradoras, entrevista marcha $\mathrm{Ni}$ Una Menos, junio de 2017).

Queremos respeto, que se hablen de esos temas, que no se escondan, no se deja hablar, que se dé educación sexual y que se tomen medidas por el tema de violencia adentro de los cursos (Tomasini y colaboradoras, entrevista marcha 8M, marzo de 2018).

Tal como fue analizado en otros trabajos (Elizalde, 2018a; Elizalde y Mateo, 2018), la enunciación de sus reclamos presenta una particular marca generacional: están ahí porque 'matan a las pibas', por las 'chicas' asesinadas, desaparecidas, violadas o acosadas, porque tienen 'miedo a salir a la calle como joven' y padecen acoso callejero, porque quieren cambiar el machismo en la vida cotidiana y cuestionar los 
modelos hegemónicos de belleza, demandar educación sexual en sus escuelas y afirmarse como sujetos políticos con derecho a la "voz propia". Ello nos hace pensar, junto con Larrondo y Ponce Lara (2019), en la simultaneidad del devenir joven, activista y feminista en la acción colectiva y cómo tal intersección es constitutiva de los procesos identitarios porque la salida a la calle con otras pares a reclamar por lo mismo tiene un efecto que las potencia y las transforma.

La práctica de 'poner el cuerpo', estar en la calle, hacer visible la protesta a través de producciones estéticas, batucadas, corridas y performances, se viene haciendo en Argentina en los encuentros nacionales de mujeres y en otras acciones feministas y del activismo de la disidencia. En los micro relatos producidos por las jóvenes ello cobra centralidad en su devenir identitario. Para muchas chicas que están participando recientemente en las marchas ese encuentro que se produce con otras en el espacio público es un punto de inflexión, les permite 'darse cuenta', 'ver cosas que antes no veían', esto es, adquieren una nueva conciencia:

Se me abrió un montón la mente y me enteré de un montón de cosas que antes yo no sabía y me encanta, me encanta poder venir a marchas, me encanta poder estar en el centro de estudiantes, poder decidir lo que yo quiero, o sea estar a favor de ciertas cosas y poder elegir mi mentalidad propia (Tomasini y colaboradoras, entrevista marcha Ni Una Menos, junio de 2018). Ver esos carteles, me di cuenta que yo también a veces me encuentro a mí misma pensando: "ah pero hoy no sé qué, ah pero no sé si estoy lo suficientemente... no sé, si tengo tal cosa que supuestamente tendría que tener o si uso lo que tendría que usar", cosas así como que te hace pensar mucho para vos misma, si vos también digamos eh te abusas a vos misma, si vos también te maltratas a vos misma. (Tomasini y colaboradoras, entrevista marcha Ni Una Menos, junio de 2018). 
[Una chica reflexiona tras contar una perfomance que vio en la marcha] Yo no me doy cuenta y yo siempre antes de los quince me ponía muy mal porque no sabía qué ponerme y decía: "no esto me queda mal, estoy gorda, cómo me voy a pintar así" y era como me hacía super mal, me sentía muy mal porque no estaba a las expectativas de lo que se esperaba o lo que tenía que estar y te das cuenta y vas cayendo en cuenta de lo que vos misma te estás haciendo (Tomasini y colaboradoras, entrevista grupal con jóvenes autoconvocadas, Escuela Católica, 2016).

Los cuerpos se mueven en el espacio físico pero fundamentalmente se mueven de las normatividades que los han constituido. Como señala Mari Luz Esteban Galarza (2009) la "carnavalización" es un ámbito generador de formas específicas de lenguaje y comunicación que abre camino hacia otras prácticas de producción de subjetividad. Pintarse el rostro, cantar, bailar, hacer corridas, hacer una performance o estar ahí poniendo el cuerpo en medio de la protesta, es una instancia de politización. En esa escena donde se vibra con otras, en un clima que es descripto por su intensidad afectiva, se hace posible conmover ciertos supuestos y resignificar costumbres que habían pasado inadvertidas o quedaban como registro de un malestar difuso. De este modo, como plantea Nayla Vacarezza (2018), se ponen a circular tonalidades afectivas relacionadas con la unión, la alegría y el orgullo, que buscan activar fuerzas para la transformación de las condiciones sociales que generan el sufrimiento que se denuncia.

\section{La politización juvenil: entre tensiones, acuerdos y desacuerdos}

Todos los temas señalados hasta acá como motivos para ir a las marchas aparecen articulados con una fuerte demanda por educación sexual al compás de sus experiencias y realidades. Es un reclamo al Estado, por la aplicación de la Ley de Educación Sexual Integral, y a la institución educativa, por la inclusión en la curricula o 
en las actividades pedagógicas. No obstante, construyen este tópico desde un marco de agencia; es decir, aunque esperan que la escuela coloque el tema o en las clases 'se brinde información', también se vuelven protagonistas en la promoción u organización de acciones:

Hace poco tiempo que se da [educación sexual] y sobre todo incentivado por los estudiantes en realidad, y las estudiantes, que venimos a pedir que la educación sexual no sea solamente desde el punto de vista biológico, y traemos nosotros, o sea, alzamos la voz. (Tomasini y colaboradoras, entrevista marcha 8M, marzo 2017).

Este sentido de hacer o accionar grupalmente en la vida cotidiana de la escuela se acompaña, para algunas chicas, de la sensación de agravio cuando quieren instalar un tema, proponen una actividad o sencillamente replican algún comentario o actitud que consideran machista. De modo característico, surgen las etiquetas de 'agresivas' o 'feminazis', por la vehemencia con la que se posicionan. Si bien esto aparece como dato transversal a los distintos contextos escolares, algunas tendrían condiciones más favorables en su práctica activista, ya sea porque pueden referenciarse en espacios estudiantiles colectivos para pensar y accionar o bien porque cuentan con mayor respaldo escolar que, entre otras cosas, las apoya en el emprendimiento de actividades.

Esta alusión al modo como son afectadas por el estigma de la feminista agresiva encuentra conexión con algunas críticas que surgen en las entrevistas hacia ciertos modos que asume la protesta en la calle. Si bien es una posición minoritaria, hay cuestionamientos a las pintadas de las Iglesias o los edificios públicos y a marchar con el torso desnudo, porque refuerzan la imagen de la 'feminista violenta'. Esto operaría de modo desfavorable cuando pasan por los cursos a invitar para las movilizaciones porque reciben comentarios negativos sobre el clima de las marchas. En este punto, 
hay escazas alusiones al papel que juegan ciertos medios de comunicación en la construcción de tal imagen a través de mecanismos de focalización y repetición.

Del mismo modo hay discrepancias con ciertos reclamos presentes en las marchas. En uno de los grupos entrevistados en el año 2017, la legalización del aborto apareció como un tema con el que no todas y todos acuerdan y señalan que les ha traído conflictos como organismo de representación estudiantil. Relatan que en los días previos a las marchas aparecieron carteles anónimos en la puerta del centro de estudiantes con frases como 'matar al feto también es matar'.

Otro tema que generó controversia fue el pedido de libertad a la dirigente social Milagro Salas, cuya detención en 2016 ha sido considerada como de carácter político por diversas organizaciones de derechos humanos. Hay quienes cuestionan esta consigna porque consideran que 'politiza la marcha' para referir así a la utilización de las movilizaciones por parte del movimiento kirschnerista y los partidos de izquierda para sus propios intereses.

La oposición a la legalización del aborto así como a la consigna por la libertad de Salas, surge en el grupo de un colegio cuyos estudiantes son activos en la participación de las movilizaciones ambientales y de derechos humanos. Lo interesante a destacar aquí es el marco de sentido en el cual inscriben estos desacuerdos. Argumentan que su espacio de representación estudiantil es 'apolítico' (no alineado a ningún partido) y defienden esa impronta porque posibilita la convivencia de jóvenes de distintas adscripciones partidarias. Pero fundamentalmente interesa reparar en la concepción de feminismo que se pone en juego, ya que señalan que dichas consignas, para algunas y algunos, atentarían contra lo que sería un movimiento feminista 'inclusivo'. Desde esta perspectiva, un movimiento tal debería centrarse en los puntos donde hay consenso (violencia y femicidios) y no apartarse de lo que han denominado como 'reclamos puros' del feminismo: 
"Muchas veces se suelen solapar los reclamos, por ejemplo, en el último Ni una menos me acuerdo que veía algunas personas, grandes, chicos, diferentes edades con el cartel de Milagro Salas, hay otros matices temas que se cruzan que no sabíamos decir si pertenecen al reclamo puro de lo que es la marcha. También el aborto. Por eso a veces vamos por algunos puntos, otros irán por todos." (Tomasini y colaboradoras, entrevista grupal, junio de 2017).

Los desacuerdos señalados muestran que asumirse feminista no implica que tal identidad sea unívoca e indica la complejidad de tal proceso, ya que no clausura divergencias en temas nodales a la agenda actual del feminismo, como la demanda por el aborto legal. Aunque haya puntos en común, como lo analizó Olarte Roso (2016), existe diversidad de discursos y una necesidad de diferenciación al interior del feminismo, en un proceso de afirmación de la propia diferencia dentro de esa identidad política.

La politización, tal como lo ha propuesto Kriger (2015), es un proceso psicosociocultural complejo, de carácter intra e intersubjetivo, en el cual se re significa y reactualiza permanentemente la vida colectiva. Las y los jóvenes se politizan en una dialogicidad donde se traman convergencias tanto como desacuerdos entre sí y con los feminismos. El activismo de género en la escuela las y los ubica en un escenario de controversia y conflicto. Me interesa destacar al respecto que las atmosferas afectivas (Flatley, 2008) son constitutivas del proceso de politización, ya que no sólo enfrentan la impugnación de sus demandas o la contra argumentación y el desacuerdo, sino que asumirse como feminista o realizar alguna forma de activismo implica ser afectada por la "adherencia de malos sentimientos" (Ahmed, 2017). Algunas sienten que para fastidiarlas o herirlas las llaman 'feminazis', 'agresivas', 'violentas' o 'aborteras'. El devenir feminista las arroja a un espacio donde deben luchar por el reconocimiento ante la imagen negativa que les devuelven sus otros cercanos; como decía una chica: 'soy la loca feminista de la familia, para mis amigas y 
mis compañeros, todo re en contra'. Pero, al mismo tiempo, vivencian atmosferas reconfortantes cuando participan de las marchas $u$ otras actividades en sus colegios, porque sienten que son espacios de 'sostén', ‘apoyo' y 'solidaridad' y esto las potencia en su deseo de luchar para transformar sus realidades.

\section{Mujeres, jóvenes, feministas. La cuestión intergeneracional}

En todos los temas que mueven a participar en las marchas, como fue señalado, hay marcadores generacionales integrados a los relatos. Las muertes, los asesinatos y el miedo correlativo que esto provoca, pero también el acoso y el machismo, refiere prioritariamente al cuerpo de las jóvenes. De modo marginal la desigualdad aparece enclavada en otros marcadores sociales, como la clase o la expresión de género. Encontramos algunas menciones a la pobreza como condición que vulnerabiliza aún más a las mujeres en los casos de aborto y alusiones a la situación desfavorable de las 'chicas trans'. Es interesante señalar una conciencia difusa del privilegio de clase, ya que consideran que ellas podrían practicarse un aborto en condiciones 'seguras', a diferencia de las 'mujeres pobres'. Al mismo tiempo, el acto enunciativo de luchar por las pobres o las trans es un acto de distinción cis sexual y de clase. Esto lleva a preguntarse a quiénes construyen como sujeto protagonista de la lucha, toda vez que pelean por las otras y no con las otras.

La dimensión intergeneracional, por otra parte, merece algunas consideraciones. En el entrecruzamiento entre los estudios de género y los de juventudes ha sido posible pensar las genealogías políticas femeninas (Elizalde, 2018b) o la genealogía femenina (Olarte Roso, 2016) en las trayectorias del devenir feministas de las jóvenes. La historiado Valeria Manzano (2019) aporta una hipótesis sugerente para pensar el encuentro intergeneracional, entre las "adolescentes" y las "históricas", en el feminismo actual. Hasta años recientes, los grupos feministas habrían configurado una agenda de reclamos que delinearon un sujeto centrado en la mujer adulta, 
preferentemente madre. La irrupción de las más chicas en los feminismos, al mismo tiempo que un diálogo más fecundo entre dichos campos de conocimiento, ha hecho posible la pregunta por el vínculo cultural, político y afectivo que reúne a jóvenes y adultas en un reclamo común (Elizalde, 2018b).

En los relatos de las jóvenes aparece, por un lado, ciertas opacidades respecto de la militancia feminista antecedente, teniendo en cuenta que en Córdoba ha sido vigoroso el movimiento de mujeres que desde hace décadas reclaman por derechos sexuales y reproductivos y se manifiestan en contra de las desigualdades y violencias. La puntuación en el relato se realiza en el aquí y ahora lo cual, performativamente, construye a ésta como una lucha propia de su generación que convoca y gana la adhesión de personas más grandes:

Me parece que está claro que los que más participamos en esto somos los jóvenes, si bien me parece que cada vez vamos ganando más apoyo de gente de mayor edad digamos, pero a los jóvenes los veo... si bien siempre hay un grupo que no, pero los veo bastante interesados en defender lo que es propio (Tomasini y colaboradoras, entrevista marcha Ni Una Menos, junio de 2017). Mientras que otras chicas inscriben su participación en una genealogía familiar, donde es posible reconocer la militancia de sus madres y abuelas como parte de su proceso de subjetivación política en el feminismo (Lares y otras, 2018). Pueden reconocer y poner en valor, como sostiene Elizalde (2018b), los saberes, las experiencias y el "aguante" luchador de estas otras adultas y es en virtud de las predecesoras que se constituye el significado de la lucha presente:

A mí me motiva el hecho de que familiarmente tengo a mi abuela que era feminista y es desaparecida, entonces eso es como que me mueve a saber que dentro de mí llevo sus principios, entonces quiero seguir perpetuando eso que ella me dejó. (Tomasini y colaboradoras, entrevista marcha 8M, marzo de 2018) 
Yo vengo de una familia de militantes, mi viejo milita en un espacio, mi madre es feminista desde hace mucho tiempo entonces me crié en una casa rodeada de feminismo y desde que soy niña que tengo... cuando uno empieza a crecer y estás en la etapa de la adolescencia como que te vas dando cuenta de la importancia de dar esta batalla cultural digamos, de decir ¿por qué nos matan a una piba todos los días? (Tomasini y colaboradoras, entrevista grupal, centro de estudiantes, 14 de junio de 2017).

En estos relatos están produciendo una identidad sustentada, para algunas, en la condición de jóvenes que luchan por los problemas que las afectan genérica y generacionalmente, ya sea que enfaticen o no la identificación feminista. Mientras que para otras el feminismo inscripto en una genealogía política es un anclaje identitario. Si bien en las entrevistas la marca está puesta en el "linaje" familiar, en las marchas muchas chicas se han apropiado de la consigna: "Somos las hijas [o las nietas] de las brujas que no pudieron quemar", reconociendo así una inscripción en una genealogía política feminista trans generacional, que las une a otras con las que no han coexistido en espacio y tiempo.

\section{Reflexiones finales}

El devenir identitario de las jóvenes "adolescentes" a través del activismo de género se presenta como una instancia compleja en la cual se tensionan similitudes y diferencias, se manifiestan divergencias entre pares de edad, así como diferentes posicionamientos en el diálogo intergeneracional. Tal devenir se construye a partir de procesos interrelacionados: agencia, intersubjetividad y conciencia.

Agencia, como posibilidad de producir efectos sociales a la vez que en sí mismas. La enunciación de los reclamos y los motivos para ir a las marchas aparece puesto en un lenguaje de acción donde relatan su protagonismo para alzar la voz, hacerse escuchar y salir a luchar en el espacio público, así como para proponer actividades en sus 
escuelas. Este protagonismo las ubica en un escenario de conflicto donde deben disputar por el reconocimiento ante el estigma de la feminista y las actitudes hirientes de algunos otros cercanos. La politización acontece, así, en determinados climas emocionales que van desde la hostilidad hasta el júbilo, con innumerables situaciones intermedias de emociones difusas o de co existencia de tonalidades afectivas; cualquiera sea su valencia, lo que parecen expresar las chicas es que esta afectividad las potencia en su capacidad de acción, ya sea por la necesidad de replicar o reaccionar ante la hostilidad, como por la manera en que los climas festivos intensifican su capacidad de imaginar y su deseo de hacer con otras.

Así es como el sentido de agencia no puede disociarse de la intersubjetividad: ciertas emociones, como la alegría y el orgullo, emergen al participar y estar en la calle con diversidad de personas luchado 'por lo mismo'. La calle aparece como el espacio simbólico compartido con una diversidad de otros, fundamentalmente de otras, con quienes comparten visiones de desigualdades e injusticias, aunque no se trate de concepciones homogéneas que anulen las diferencias.

Finalmente, el devenir identitario está ligado a la experiencia de una nueva conciencia del mundo que las rodea y su lugar en él, qué cosas les suceden y cómo las explican. Este aspecto aparece en los relatos en un sentido dual: 'tener conciencia de lo que pasa' las motiva a participar y, a su vez, porque se involucran y participan 'se dan cuenta' de algo que no advertían. En las marchas o en otros eventos activistas hacen una experiencia de transformación: 'abren los ojos', 'cambian la forma de ver el mundo, 'se les abre la mente', 'cambian el pensamiento', 'pueden elegir su mentalidad', se hacen 'más grandes y más fuertes' o ‘se animan'.

El entramado simbólico se va resquebrajando y en algún momento las situaciones naturalizadas se empiezan a configurar como injustas o ilegítimas. Bartky (1990, citada en Bach, 2010) planteaba que alcanzar una conciencia feminista es lograr ver aspectos de sí misma o de la sociedad que antes no se percibían, más allá que las 
chicas se consideren o no a sí mismas como feministas. Sin embargo, por momentos se construye como una conciencia que las lleva a luchar por otras (las 'mujeres pobres' o las 'chicas trans'), con poco cuestionamiento acerca del protagonismo de estos grupos en las marchas o de su escaso lugar junto a agrupaciones de estudiantes.

En estas dinámicas de participación cabe atender a las relaciones intergeneracionales: las relaciones entre las feministas históricas y "las pibas". Más allá del actual momento de acompañamiento en la lucha, por ejemplo, por el acceso al aborto legal en el país, persiste en algunas de nuestras entrevistadas cierta falta de reconocimiento de las aportaciones de las generaciones al feminismo, ya que en algunos casos se construye como una lucha propia de las "jóvenes de hoy". Sin embargo, otras pueden inscribir su participación en genealogías políticas familiares como anclaje identitario; más aún, muchas otras, al apropiarse de la consigna "Somos las hijas [nietas] de las brujas que no pudieron quemar", se reconocen a sí mismas como parte de un proceso histórico que ha venido siendo con otras antecesoras.

Una cuestión esbozada en el artículo queda abierta como interrogante: quiénes son las jóvenes que se están acercando a los feminismos en términos de clase, raza y territorios. Dicho en los términos de este trabajo, quiénes son las jóvenes y "adolescentes" que están pudiendo devenir feministas. Como dato en el caso cordobés, se observa que estas jóvenes pertenecen en general a sectores medios, muchas de ellas o bien vienen de familias con madres y abuelas activistas o bien asisten a colegios secundarios referenciados como "progresistas". Sin embargo, cabe pensar en grupos no explorados aún desde nuestra investigación para generar una nueva pregunta: en las marchas muchas jóvenes y muchos jóvenes están junto a banderas de sus agrupaciones territoriales u organizaciones barriales, así como de colectivos LGTB. Entonces ¿será que estas pertenencias interpelan más que la adscripción estudiantil a distintos sectores de la juventud? 


\section{Referencias}

Ahmed, S. (2017). La política cultural de las emociones. Ciudad de México: Centro de Investigaciones y Estudios de Género.

Alvarado, S. \& Vommaro, P. (2010). Presentación. En S. Alvarado y P. Vommaro (Comps.), Jóvenes, cultura y política en América Latina: algunos trayectos de sus relaciones, experiencias y lecturas (1996-2000) (pp.7-12). Rosario: Homo Sapiens Ediciones.

Bach, A. (2010). Las voces de la experiencia. El viraje de la Filosofía. Buenos Aires: Biblos.

Baez, J. (2014, septiembre). “Hacerse notar”. Lxs jóvenes, las sexualidades y los avatares escolares. En Voces, cuerpos y derechos en disputa. Ponencia presentada en el $3^{\circ}$ Congreso Género y Sociedad de la Facultad de Filosofía y Humanidades, Universidad Nacional de Córdoba, Argentina.

Bruner, J. (2003). La fábrica de historias. Derecho, literatura, vida. Buenos Aires: Fondo de Cultura Económica.

Di Marco, G. (2010). Los movimientos de mujeres en la Argentina y la emergencia del pueblo feminista. La Aljaba, Segunda época, 14, 51-67. Recuperado de http://www.scielo.org.ar/pdf/aljaba/v14/v14a03.pdf

Elizalde, S. (2018a). Las chicas en el ojo del huracán machista. Entre la vulnerabilidad y el "empoderamiento". Cuestiones Criminales, Universidad Nacional de Quilmes, (1)1, 22-40.

Elizalde, S. (2018b). "La revolución de las pibas". Apropiaciones generacionales del feminismo y construcción de genealogías de lucha y "sororidad". En Actas de la VI Reunión Nacional de Investigadorxs en Juventudes de Argentina. Recuperado de: http://redjuventudesargentina.com/wpcontent/uploads/2019/08/GT5-VI-ReNIJA-C\%C3\%B3rdoba-2018.pdf 
Elizalde S. \& Mateo N. (2018) Las jóvenes: entre la "marea verde" y la decisión de abortar. Salud Colectiva, 14(3), 433-446. doi: 10.18294/sc.2018.2026.

Esteban Galarza, M. (2009). Identidades de género, feminismo, sexualidad y amor: Los cuerpos como agentes. Política y Sociedad, $46(1$ y 2), 27-41. Recuperado de https://dialnet.unirioja.es/servlet/articulo?codigo=3141614

Flatley, J. (2008). Affective Mapping. Melancholia and the politics of modernism. London: Harvard University Press.

Gómez Ramírez, O. \& Reyes Cruz, L. (2008). Las jóvenes y el feminismo: ¿indiferencia o compromiso?. Estudios Feministas, 16(2), 387-408. Recuperado de http://www.scielo.br/pdf/ref/v16n2/05.pdf

Hall, S. (2003). ¿Quién necesita “identidad? En S. Hall y P. du Gay (Comps.), Cuestiones de identidad cultural (pp. 13-39). Buenos Aires-Madrid: Amorrortu.

Kriger, M. (2015). La política y lo político: del dilema al problema. Análisis de las argumentaciones y propuestas de acción de jóvenes estudiantes de la Ciudad de Buenos Aires. De Prácticas y discursos, 4(4). Recuperado de http://ppct.caicyt.gov.ar/index.php/depracticasydiscursos/article/view/7309/6583

Lares, Y.; Nimo, P.; Morales, G. \& Tomasini, M. (2018, noviembre). Construirse como feminista en la escuela secundaria. La participación de estudiantes en acciones colectivas que abordan temas de género y sexualidad. Ponencia presentada en la VI Reunión Nacional de Investigadores de Juventudes Argentinas. Protagonismos juveniles a 100 años de la Reforma Universitaria. Organizada por la REIJA y la Universidad Nacional de Córdoba. Recuperada de: http://redjuventudesargentina.com/wp-content/uploads/2019/08/GT5-VIReNIJA-C\%C3\%B3rdoba-2018.pdf

Larrondo, M. \& Ponce Lara, C. (2019). Activismos feministas jóvenes en América Latina. Dimensiones y perspectivas conceptuales (21-38). Activismos 
feministas jóvenes: emergencias, actrices y luchas en América Latina. Ciudad Autónoma de Buenos Aires: CLACSO.

Lopes de Oliveira, M. \& Almeida Camilo, A. (2014). Participação política juvenil e constituição de gênero: uma questão para a psicologia do desenvolvimento. AtheneaDigital, 14(2), 95-115. Recuperado de http://dx.doi.org/10.5565/rev/athenea. 1160

Manzano, V. (2019). Feminismo y juventud en la Argentina del siglo XX. En Larrondo, M. \& Ponce Lara, C. (Edits.) Activismos feministas jóvenes: emergencias, actrices y luchas en América Latina (41-58). Ciudad Autónoma de Buenos Aires: CLACSO.

Olarte Roso, N. (2016). Mujeres Jóvenes en México y sus devenires feministas (Tesis de Maestría). Centro de Investigaciones y Estudios Superiores en Antropología Social, México Recuperado de https://ciesas.repositorioinstitucional.mx/jspui/handle/1015/217

Ortiz-Ruiz, N. (2016). ¿Qué mueve a las organizaciones juveniles? Revista Latinoamericana de Ciencias Sociales, Niñez y Juventud. 14(1), pp. 531-543. doi:10.11600/1692715x.14136260215

Renold, E. \& Ringrose, J. (2008). Regulation and rupture: Mapping tween and teenage girls' resistance to the heterosexual matrix. Feminist theory, 9(3), 313-338. Recuperado de https://doi.org/10.1177/1464700108095854

Ringrose, J. \& Renold, E. (2016). Teen Feminist Killjoys? Mapping Girls' Affective Encounters with Femininity, Sexuality, and Feminism at School. In C. Mitchell \& C. Rentschler (Eds.). Girlhood and the Politics of Place (pp. 104-121). New York: Berghahn Books.

Tincknell, E. (2011). Scouring the Abject Body: Ten Years Younger and Fragmented Feminity under Neoliberalism. In G. Rosalind \& C. Scharff (Eds.), New 
Feminities. Postfeminism, Neoliberalism and Subjectivity (pp. 83-94). Great Britain: Palgrave Macmillan.

Vacarezza, N. (2018). Perejil, agujas, pastillas. Objetos y afectos en la producción visual a favor de la legalización del aborto en Argentina. En Busdygan, D. (Coord.) Aborto. Aspectos normativos, jurídicos y discursivos (pp. 195-212). Ciudad de Buenos Aires: Biblos.

Vázquez, M., Vommaro, P., Núñez, P. \& Blanco, R. (2017). Militancias juveniles en la Argentina democrática Trayectorias, espacios y figuras de activismo. Buenos Aires: Imago Mundi.

\section{Declaración de contribución de autores}

MET contribuyó en la totalidad del artículo.

\section{Editor se sección}

La editora de sección de este artículo fue Alejandra López.

ORCID ID: 0000-0001-9975-7297

\section{Formato de citación}

Tomasini, M.E. (2020). ¿Qué mueve a las jóvenes a participar? Activismo de género y construcción de identidades en estudiantes de escuelas secundarias de Córdoba, Argentina. Psicología, Conocimiento y Sociedad, 10(2), 123-149. doi: http://dx.doi.org/10.26864/PCS.v10.n2.6 